\title{
Sexual harassment allegations against doctors: Facts and fiction
}

\author{
Dayapala A*, Rajapaksha WRAS \\ District General Hospital, Negombo \\ *Corresponding author: Tel: 0094-724158935. E-mail address:adayapala@yahoo.com
}

MLJSL.Vol 3. No 1. March. pp 22-24

\begin{abstract}
The doctor - patient relationship is unique due to its intimacy, confidentiality and asymmetry of power. The very nature of it can result in abuse of patients by doctors and this has prompted the profession to introduce codes of conduct for doctors, namely medical ethics from the very beginning of the organized medical practice.

Medical ethics especially prohibit sexual relationships with patients and their family members. Sri Lanka Medical Council categorizes such relationships as acts of serious professional misconduct. But sexual harassment allegations against doctors by patients are reported from time to time and a proportion of them are true allegations. However, there is ample room for false allegations too.
\end{abstract}

Misunderstanding of examination procedures by patients, psychiatric disorders of patients such as "transference", hallucinations induced by drugs - especially sedatives and anaesthetic agents - and personal grudges arising out of unfulfilled wishes as in insurance claims have been recognized as some reasons for false allegations.

Though clinicians are at a higher risk, forensic practitioners cannot be considered totally immune to such allegations. As these allegations are very damaging to the individual practitioners as well as to the whole profession, preventive measures must be adopted.

Proper application of the concept of "informed consent" in doctor-patient relationship and insistence on good ethical practices such as the presence of a chaperone under all circumstances are simple practical measures that can be adopted to minimize such false allegations.

Doctors must be aware of the potential risks under specific circumstances for their own safety, integrity of the profession and the wellbeing of their patients.

Key words- Medical ethics, Sexual harassments, false allegations, Informed consent, Good ethical practices

\section{Introduction}

The doctor - patient relationship is unique due to its intimacy, confidentiality and asymmetry of power. Potential vulnerability of this relationship for abuse has been recognized by the forefathers of the profession prompting them to propose codes of conducts for doctors in the form of medical ethics. The Hippocratic Oath is the best example for such attempts. Among prohibited conducts in the doctorpatient relationship, zero tolerance for sexualized behaviours has very good reasons. Doctors are powerful authority figures and 
exploiting patients' trust to serve their own sexual gratification is similar to abusing a child by its parent $[1,2]$.

Sri Lanka Medical Council considers that a doctor entering into an emotional or sexual relationship with a patient or with a member of the patient's family which disrupts the patient's family life or otherwise damages or causes distress to the patient or his or her family is culpable of serious professional misconduct [3].

But we see news items about sexual harassments of patients by doctors from time to time. Such news items draw quick and aggressive attention of the public, doctors as well as health authorities. Irrespective of the truth of such allegations or the outcome of investigations, the alleged doctor as well as the profession as a whole faces embarrassment in society, in hospitals and even in their homes [1]. Such sexual harassments do exist and the reported cases can only be the tip of the iceberg [4].

Concerned parties must explore all possibilities to prevent such abuses by doctors. If proven beyond reasonable doubt, most severe penalties possible must be enforced on the abusers.

But it must be borne in mind that there is ample room for false allegations due to various reasons. They include misunderstanding of examination procedures, psychiatric disorders of patients, as well as drug induced hallucinations and personal grudges against doctors $[1,5,6]$.

Misunderstanding can arise due to incomplete or lack of attempts by the doctor to explain the examination procedures to a patient. This is directly connected to the issue of informed consent.

As medical students medical practitioners have been taught that they have to examine the healthy organ first when a patient is complaining about something wrong in one of the paired organs [7]. When a doctor attempt to examine the right breast of a woman who is complaining about a lump in her left one, his action could be misunderstood. Almost all the doctors have encountered patients who tried to show the "correct "side when the doctor started to examine the "wrong "side first. Such misinterpretation can also arise when a doctor wants to examine the hip region, thinking of referred pain in a patient complaining of pain in the knee [7].Such examples are numerous in clinical practice. One remedy for such misunderstanding thereby preventing the false allegations is the "informed consent" where the patients and guardians are educated adequately about the line of thinking of the doctor in relation to the patient's complaint.

Some drugs have been reported to induce hallucinations. Some of those hallucinations are sexual in nature. They can lead to false allegations against doctors. Such drugs include propofol, a drug widely used to sedate patients and ketamine which is also used to induce and maintain general anesthesia. Diazepam and short duration sedatives like midazolam also can induce such hallucinations. Under propofol, any stimulation to the chest, like the removal of electrodes or the inflation and deflation of a blood pressure cuff and even asking the patient to squeeze the doctor's fingers have triggered hallucinations of sexual nature. Midazolam also can induce "hallucinations," "emergence delirium" and "dreaming." Diazepam can cause "delusions (holding false beliefs that cannot be changed by facts)" and "changes in sexual desire." Ketamine can cause psychological manifestations varying in severity between pleasant dream-like states, vivid imaginary hallucinations, and emergence delirium." According to medical literature these side effects, though uncommon with modern medicine, have resulted in false and careercrushing allegations against practitioners [6].

Psychiatric disorders and borderline personalities may also result in false allegations. Transference is such a phenomenon where a person unconsciously transfers feelings and attitudes from a person or situation in the past on to a person or situation in the present. At times the unsuspecting doctor can be a victim due to allegations arising from such psychological disorders in patients [8]. 
Personal grudges due to unfulfilled ambitions such as failure to obtain a favorable report from a doctor for insurance purposes etc. has also resulted in false sexual assault allegations [5].

Good ethical practices such as insisting on the presence of a chaperone of same sex as the patient during the doctor-patient interaction cannot be overemphasized in preventing false allegations under these circumstances.

In one study it has been found that sexual harassment charges were mostly found in Gynecology and Obstetrics (24.67\%), followed by General Surgery, Pediatrics, Cardiology, Psychiatry, and Urology and Traumatology [4]. But forensic practitioners can also be vulnerable for such charges [9]. A forensic practitioner examining a "difficult hymen in forensic sense" with various examination techniques for a longer period can give wrong impression to the patient or even to the guardian or to an inexperienced chaperone. Similarly, in a case of suspected wife battery, asking the woman to expose the covered areas to look for other injuries can lead to misunderstanding. In the mortuary the forensic practitioners are expected to detect hidden violence such as sexual assaults [10]. If a casual visitor to the mortuary or a new postmortem attendant sees the doctor paying "undue attention" to the genitalia of a young girl found dead due to hanging or poisoning, the doctor's action can be misunderstood.

Increased awareness about the possibility of real and false allegations of sexual harassments among doctors, patients and all stakeholders is essential in prevention of these unfortunate incidents. This is essential for upholding the dignity of the profession and ultimately the wellbeing of the patients. After all, the old saying "Prevention is better than cure "cannot be more relevant here than anywhere else for the health of doctors.

\section{References}

1. Galletly CA. Crossing professional boundaries in medicine: the slippery slope to patient sexual exploitation. Medical Journal of Australia 2004; 181 (7): 380383.

2. Council on Ethical and Judicial Affairs, American Medical Association, "Sexual Misconduct in the Practice of Medicine," Journal of the American Medical Association, 1991; 226:2741-2745.

3. Guidelines on Ethical Conduct for Medical \& Dental Practitioners registered with the Sri Lanka Medical Council, Sri Lanka Medical Council, 2003.

4. Cohen C, Kelian A L, Oliveira RA, et al. Sexual Harassment in the Physician-Patient Interaction: Analysis of Charges against Doctors in the State of São Paulo. Clinics (Sao Paulo). 2009 November; 64(11): 1075-1083.

5. Sexual Misconduct Claims Review Penal. http://www.thedoctors.com/KnowledgeCe nter/PatientSafety/articles/CON_ID_00032 0

6. Doctor's possible defense: alleged sex assaults were hallucinations. http://old.postgazette.com/pg/08176/89209952.stm\#ixzz2ENBVWUoB

7. Clain A, Ed. Hamilton Baily's Demonstration of Physical Signs in Clinical Surgery.IOP Publishing Ltd. Bristol. 1986.

8. Hughes $P$, Kerr I. Transference and counter-transference in communication between doctor and patient .Advances in Psychiatric Treatment (2000) 6: 57-64.

9. Prosecution argues renowned forensic psychiatrist fit to stand trial on patient sexual abuse charges. http://www.calgaryherald.com/health/735 1594/story.html\#ixzz2DtG6LqAO

10. Spitz WU. Asphyxia: in Spitz and Fisher's Medico-legal Investigation of Death 4th ed. 2004 Charles c Thomas publishers Itd.

\section{Contribution of authors}

Designing - AD

Writing the manuscript $-A D$, WASRS

Revising the manuscript-AD, 